\title{
Phonological Processes of Three Indonesian Children Aged Between 1;8 and 2;6
}

\author{
Patuan Raja \\ Language and Arts Education Department, Pedagogy and Education Faculty, \\ Lampung University, Bandar Lampung, Indonesia \\ e-mail: raja_pid@yahoo.com
}

\begin{abstract}
Children are believed to employ universal processes in simplifying adult language words to match their developing phonology. The present paper is intended to describe the phonological processes used by three Indonesian children aged between 1;8 and 2;6. There is an indication that the utilization of the processes might be not only quantitatively but also qualitatively age-related, and that the processes might actually be of three types: universal (species-specific), local (language-specific), and idiosyncratic (individual-specific).
\end{abstract}

Key words: phonological process, child language, universal

Children's versions of adult language words are noticeably phonologically simpler. This simplification has been observed to start when they have produced their $50^{\text {th }}$ word (Menyuk, Menn, \& Silber, 1986). In other words, children seem to start the productive creation of their phonological system when they are in the Telegraphic Stage, which usually starts at age 1;6 (Ingram, 1989). Ingram (1986, p. 223) states, "Between the ages of 1;6 and 4;0 the young child undergoes considerable development in phonological ability.” The phonological simplification of adult words is called "phonological processes" by Stampe quoted in Ingram (1986, p. 223). These processes are said to be universal since every child is born with the facility to simplify speech in a consistent way.

Ingram (1986) outlines the phonological processes which he claims to be generally used by children between 1;6 and 4;0 in the acquisition of English, French, Hungarian, Polish, Estonian, German, and Romanian, all of which-it should be noted-belong to the Indo-European language family. He classifies these processes into three groups: substitution (stopping, fronting, gliding, vocalization, and vowel neutralization), assimilation (voicing, velar assimilation, labial assimilation, denasalisation, http://www.petra.ac.id/ puslit/journals/dir.php?DepartmentID=ING 
and progressive assimilation), and syllable structure processes (cluster reduction, deletion of final consonant, deletion of unstressed syllable, and reduplication). Altogether, he lists fourteen processes. However, Raja $(1998,2000)$ notices that not all of these fourteen processes are used by his Indonesian acquiring subjects, while at the same time his two subjects were observed to employ, with high productivity, some processes which are not mentioned by Ingram (1986).

The present paper is intended to discuss the phonological processes utilized by three Indonesian children aged between 1;8 and 2;6 in simplifying adult language words to match their developing phonological competence.

\section{METHODOLOGY}

The three children were Mara, Mogi, and Mika. Their corpus data, in the form of naturally occurring utterances, were obtained through three separate observations (see Table 1). The data were analyzed qualitatively, by comparing their 'imperfect' phonological forms against the target adult language forms. It should be emphasized that what is meant by target language here is the language they had been exposed to, i.e., the language of those immediately around them who predominantly spoke an informal variety of Indonesian, which may phonologically be a little different from the standard one. For example, the standard expressions pedas 'chilly hot', pakai 'wear, use', taruh 'put', and ketiak 'armpit' are usually pronounced

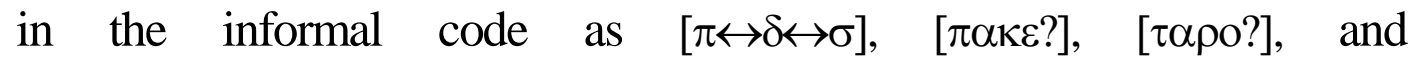

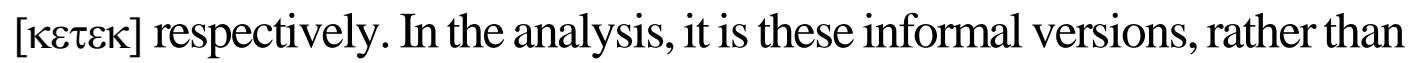
the standard ones, which are considered the target forms.

Table 1. Three Observations

\begin{tabular}{lccc}
\hline \multicolumn{1}{c}{ Aspects } & Mara & Mogi & Mika \\
\hline Length of observation & 72 days & 37 days & 1 year \\
Age at the start & $1 ; 7(13)$ & $1 ; 7(1)$ & $1 ; 6(0)$ \\
Age at the end & $1 ; 9(22)$ & $1 ; 8(6)$ & $2 ; 6(0)$ \\
Words produced & 320 & 299 & 743 \\
Phonological variants used & 580 & 580 & 1895 \\
\hline
\end{tabular}




\section{FINDINGS AND DISCUSSION}

\section{Children's Phonological Variants}

The children's pronunciation of the target language words may be classified into five classes (see Table 2): simplified adult forms, replicas, idiosyncratic forms, prosodic forms, and unaccountables. Simplified adult forms are the children's vocalizations which are taken to be the results of phonological processes. As many as 482 of Mara's 580 variants (or 83.10\%), 525 of Mogi's (90.51\%), and 1650 of Mika’s (87.07\%) belonged to this type. This specific type will be discussed in greater detail later; however, it is interesting to note presently that Mara produced a considerably lower percentage than Mogi or Mika. Stampe, quoted in Ingram (1986), regards a child's phonological development as a gradual loss of these simplifying phonological processes. Accordingly, the percentage of their simplified adult forms taken as a basis and their age difference taken into account, Mara seemed to be a bit more advanced in his phonological development than the other two children.

\section{Table 2. Classification of Variants}

\begin{tabular}{|c|c|c|c|c|c|c|c|}
\hline \multirow{2}{*}{ No } & \multirow{2}{*}{ Type } & \multicolumn{2}{|c|}{ Mara 1;10 } & \multicolumn{2}{|c|}{ Mogi 1;8 } & \multicolumn{2}{|c|}{ Mika 2;6 } \\
\hline & & No & $\%$ & No & $\%$ & No & $\%$ \\
\hline 1 & $\begin{array}{l}\text { Simplified Adult } \\
\text { Forms }\end{array}$ & 482 & 83.10 & 525 & 90.51 & 1650 & 87.07 \\
\hline 2 & Replicas & 73 & 12.58 & 46 & 7.93 & 188 & 9.92 \\
\hline 3 & Idiosyncratic Forms & 23 & 3.96 & 5 & .86 & 28 & 1.47 \\
\hline 4 & Prosodic Forms & 2 & .34 & 4 & .68 & 9 & .47 \\
\hline 5 & Unaccountables & 0 & .00 & 0 & .00 & 20 & 1.05 \\
\hline & Total & 580 & 99.98 & 580 & 99.98 & 1895 & 99.98 \\
\hline
\end{tabular}

Replicas are the children's vocalizations which match adult

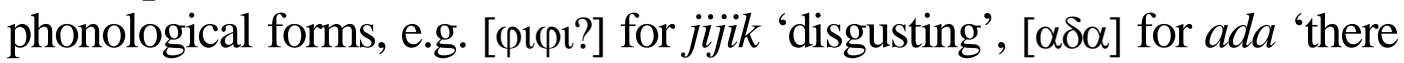
is', and $[1 \beta \mathrm{v}]$ for ibu 'mom'. Idiosyncratic forms are idiosyncratic vocalizations which are not normally found in adult language lexicon. Examples are [ $\pi \leftrightarrow \pi \leftrightarrow \eta]$ for car, Mogi's [B] for stomach, and Mika's [B] for blowing. As many as 23 (3.96\%) of Mara's, 5 (.86\%) of Mogi's, and 28 (1.47\%) of Mika's variants fell into this type. Prosodic forms, following Waterson's Prosodic Theory (Ferguson \& Garnica, 1975), are 
vocalizations which are not replicas of adult language words, not idiosyncratic forms since there is decidedly an adult word element in them, and not adaptation either since the available phonological processes cannot account for the adaptation without lengthy, forced extension. Examples of

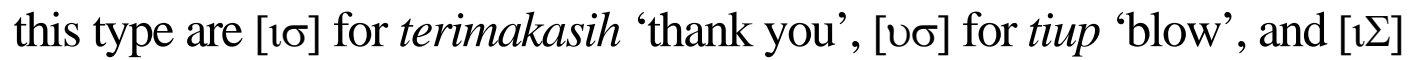
for sisir 'comb'. As many as 2 (.34\%) of Mara's, 4 (.68\%) of Mogi's, and $9(.47 \%)$ of Mika's variants were categorized as prosodics. The last type, unaccountables, was not found with Mara and Mogi and could not be classified as any one of the previous types. As many as $20(1.05 \%)$ of Mika's 1895 variants were classified as unaccountables.

\section{Phonological Processes}

As has been said previously, simplified adult forms are the result of phonological processes that children apply to adult language words. Ingram (1986) outlines the phonological processes most commonly used by children aged between 1;6 and 4;0 in the acquisition of English, French, Hungarian, Polish, Estonian, German, and Romanian-all belong to the Indo-European language family (Crystal, 1987). These processes are classified into three groups: substitution, assimilation, and syllable structure processes. Faingold (1990) asserts that substitution is a context-free process, i.e., it is a sound change which is not caused by the neighboring sounds, and that assimilation is a context-motivated process, i.e., it is a sound change which is brought about by the neighboring sounds. As outlined by Ingram (1986), substitution includes five processes: stopping, fronting, gliding, vocalization, and vowel neutralization; assimilation comprises five processes: voicing, velar assimilation, labial assimilation, denasalization, and vowel assimilation; and syllable structure embraces four processes: cluster reduction, final consonant deletion, unstressed syllable deletion, and reduplication. To these original fourteen processes, Raja (1998) added as many as eleven processes to account for his subject's phonological processes, making the total twenty-five. To these twenty-five, Raja (2000) added another two, making the total twenty-seven. These twenty-seven processes turned to be insufficient to account for the phonological processes employed by Mika. Thus, six more were added, making the total thiry-three (Raja, 2003). (see Table 3).

\section{Table 3. Phonological Processes}




\begin{tabular}{|c|c|c|c|c|c|c|c|}
\hline \multirow{2}{*}{ No } & \multirow{2}{*}{ Processes } & \multicolumn{2}{|c|}{ Mara 1;10 } & \multicolumn{2}{|c|}{ Mogi 1;8 } & \multicolumn{2}{|c|}{ Mika 2;6 } \\
\hline & & No & $\%$ & No & $\%$ & No & $\%$ \\
\hline \multicolumn{8}{|c|}{ Substitution } \\
\hline [1] & Affricating & 10 & 2.07 & 39 & 7.42 & 89 & 4.70 \\
\hline [2] & Backing & 65 & 13.48 & 94 & 17.90 & 359 & 18.94 \\
\hline & Detrilling & 18 & 3.73 & 0 & .00 & 1 & .05 \\
\hline & Devoicing & 21 & 4.35 & 4 & .76 & 17 & .90 \\
\hline [5] & Fricating & 0 & .00 & 0 & .00 & 5 & .26 \\
\hline 6 & Fronting & 73 & 15.14 & 50 & 9.52 & 26 & 1.37 \\
\hline 7 & Gliding & 24 & 4.97 & 4 & .76 & 190 & 10.03 \\
\hline & Glottalizing & 0 & .00 & 0 & .00 & 14 & .74 \\
\hline & Lowering & 0 & .00 & 0 & .00 & 46 & 2.43 \\
\hline [10] & Nasaling & 40 & 8.29 & 52 & 9.90 & 140 & 7.39 \\
\hline [11] & Raising & 0 & .00 & 0 & .00 & 69 & 3.64 \\
\hline & Stopping & 9 & 1.86 & 28 & 5.33 & 30 & 1.58 \\
\hline & Vocalization & 0 & .00 & 0 & .00 & 0 & .00 \\
\hline [14] & Voicing ( $\neq 23$ Voicing) & 0 & .00 & 0 & .00 & 14 & .74 \\
\hline & Vowel Neutralization & 9 & 1.86 & 7 & 1.33 & 0 & .00 \\
\hline [16] & Zeroing & 19 & 3.94 & 12 & 2.28 & 129 & 6.81 \\
\hline \multicolumn{8}{|c|}{ Assimilation } \\
\hline [17] & Alveolar Assimilation & 13 & 2.69 & 4 & .76 & 15 & .79 \\
\hline & Denasalization & 0 & .00 & 0 & .00 & 0 & .00 \\
\hline [19] & Glottal Assimilation & 6 & 1.24 & 0 & .00 & 0 & .00 \\
\hline & Labial Assimilation & 3 & .62 & 0 & .00 & 7 & .37 \\
\hline [21] & Stop Deletion & 20 & 4.14 & 1 & .19 & 14 & .74 \\
\hline & Velar Assimilation & 2 & 41 & 3 & .57 & 53 & 2.80 \\
\hline & Voicing ( $\neq 14$ Voicing) & 1 & .20 & 1 & .19 & 0 & .00 \\
\hline & Vowel Assimilation & 9 & 1.86 & 12 & 2.28 & 68 & 3.59 \\
\hline \multicolumn{8}{|c|}{ Syllable Structure Process } \\
\hline [25] & Addition \{nasal, stop, glide\} & 0 & .00 & 20 & 3.81 & 29 & 1.53 \\
\hline & Cluster Reduction & 5 & 1.03 & 1 & 19 & 17 & .90 \\
\hline [27] & Deletion with Retention & 1 & .20 & 59 & 11.24 & 34 & 1.79 \\
\hline 28 & Final Consonant Deletion & 5 & 1.03 & 17 & 3.24 & 66 & 3.48 \\
\hline [29] & Final Vowel Deletion & 0 & .00 & 0 & .00 & 2 & .11 \\
\hline [30] & Initial Consonant Deletion & 189 & 39.21 & 62 & 11.81 & 665 & 35.09 \\
\hline 31 & Reduplication & 52 & 10.78 & 73 & 13.90 & 88 & 4.64 \\
\hline 32 & Unstressed Syllable Deletion & 159 & 32.98 & 338 & 64.38 & 490 & 25.86 \\
\hline [33] & Unstressed Syllable Substitution & 72 & 14.93 & 71 & 13.52 & 288 & 15.20 \\
\hline
\end{tabular}

Note: Square brackets [...] indicate processes not reported by Ingram (1986)

\section{Substitution}


Substitution is a context-free process, i.e., it is a speech sound change which does not seem to be triggered by any neighboring sounds. Under this sub-class, there are as many as sixteen processes: Process 1 through Process 16.

1. Affricating. A stop or a fricative is changed to an affricate. This process was found in 10 (or 2.07\%) of Mara's 580 variants, 39 (or 7.42\%) of Mogi's 580 variants, and 89 (4.70\%) of Mika's 1895 variants (see

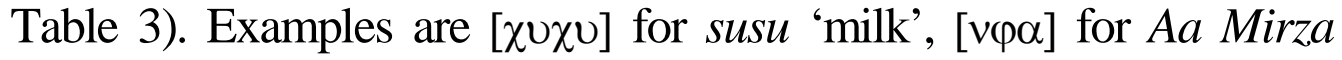
'Elder Brother Mirza', and [ $\alpha \chi \cup \kappa]$ for masuk 'enter'. It seems that Mogi had a slightly greater preference for this process compared with the other two children. On the other hand, judged from the percentage and age differences and given the observation that Mara might have been showing a rather advanced phonological development, it might be the case that as children grow older they depend less and less on this process.

2. Backing. A relatively front consonant is changed to a relatively back one. This process was found in 65 (13.48\%) of Mara's, 94 (17.90\%) of

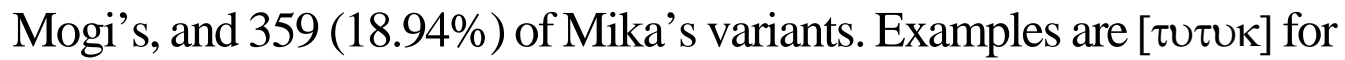
tutup 'close', $[\beta \mathrm{oN}]$ for balon 'balloon', and $[\mu \alpha \mathrm{N}]$ for mam 'eat'. Judged from the percentages, it seems that all the three children had a mild preference for this particular process.

3. Detrilling. Alveolar trill $[\rho]$ is changed to alveolar approximant $[\lambda]$. This process was found in 18 (3.73\%) of Mara's and 1 (.05\%) of Mika's variants. Mogi did not use this process. Examples are $[\alpha \lambda \alpha]$ for Mara 'Elder Brother Mara' and $[\alpha \lambda \alpha]$ for tentara 'soldier'. Considering the previously discussed observation that Mara at the age 1;10 might be showing an advanced phonological development and considering the fact that Mogi did not use this process at all while Mika used it only in one of his 1895 variants, it might be inferred that Process 3 Detrilling is a phonological process employed only by children at later stages of development - this definitely calls for further investigation. Younger children might tend to use other strategies when dealing with the alveolar trill $[\rho]$, such as nasaling, gliding, zeroing, or even syllable deletion.

4. Devoicing. A voiced consonant is changed to a homorganic voiceless one. This process was found in 21 (4.35\%) of Mara's, 4 (.76\%) of Mogi's, and 17 (.90\%) of Mika's variants. Examples are [ $\tau \alpha \tau \alpha]$ for

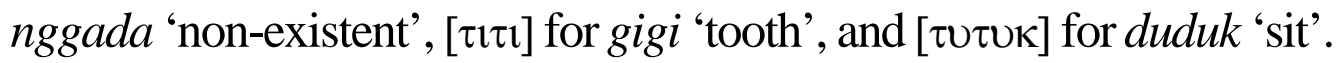


Judged from the percentage difference, it seems that Mara had a preference for this process.

5. Fricating. A non-fricative is changed to a fricative. This process was not used by Mara or Mogi, and was found in 5 (.26\%) of Mika's

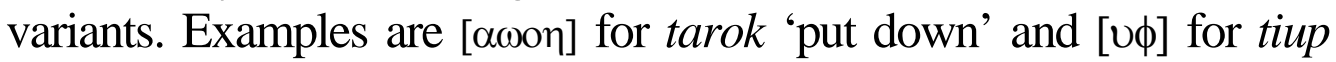
'blow'.

6. Fronting. A relatively back consonant or vowel is changed to a relatively front one. This process was found in 73 (15.14\%) of Mara's, 50 (9.52\%) of Mogi's, and 26 (1.37\%) of Mika's variants. Examples

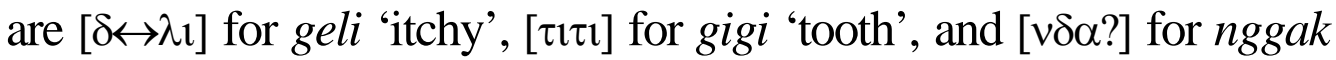
'no'. The difference in percentage might perhaps be related to the fact in the analysis of Mara's and Mogi's corpus vowel changes were included in this process, while in the analysis of Mika's corpus vowel changes were examined based on the open-close axis, i.e. the height of the tongue position, thus resulting in Processes 9 Lowering and 11 Raising.

7. Gliding. Ingram (1986) defines this process as a change by which liquids $[\lambda]$ and $[\rho]$ are changed to glides $[\omega]$ or $[\psi]$. This process was found in 24 (4.97\%) of Mara's, 4 (.76\%) of Mogi's, and 190 (10.03\%) of Mika's variants. Mogi did limit his gliding to liquids, but Mara and Mika did not. Mara applied this process also to $[\pi],[\mu],[v]$, [N], and [ $\sigma]$;

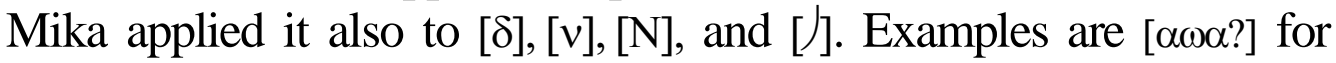

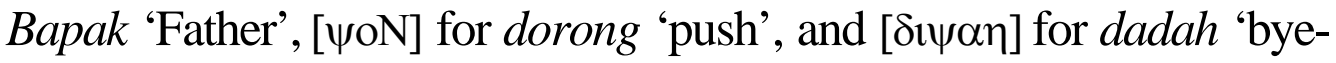
bye'. The low percentage of Mogi's utilization of this process shows that he had a great preference against it, and this might be explained by the fact that when faced with adult words containing medial-positioned liquids $[\lambda]$ and $[\rho]$, he seemed to rely more on Process 27 Deletion With Retention, for which he had a great preference, thus, for example, producing $[\beta \mathrm{oN}]$ for balon 'balloon', $[\beta \mathrm{i}]$ for beli 'buy', $[\beta \mathrm{v} \mu]$ for belum

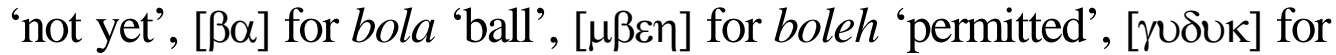

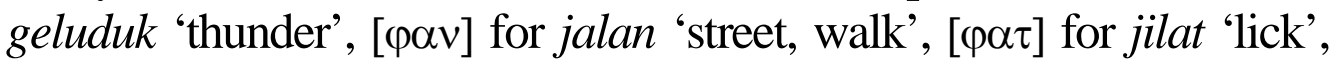

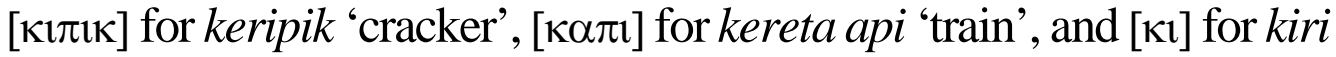
'left'.

8. Glottalizing. A non-glottal is changed to a glottal. This process was not used by Mara or Mogi, and was found in 14 (.74\%) of Mika's variants.

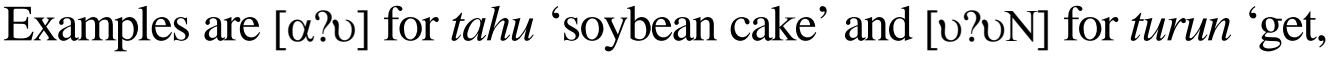
climb down'. 
9. Lowering. A relatively high vowel is changed to a relatively low one. This process was not used by Mara or Mogi, and was found in 46

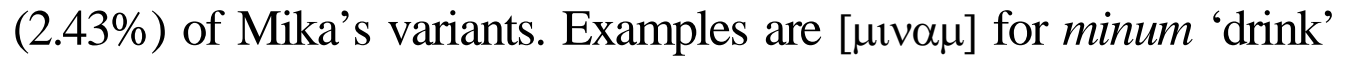
and $[\tau \alpha \pi \mathrm{l}$ ] for topi 'hat'. Maximum contrast, which has been proposed as one principle of early phonological development (Cruttenden, 1979 and Carroll, 1986), and which was originally conceived by Jakobson (Dale, 1976), might explain why Mika changed a relatively high to a relatively low vowel in a number of his variants, i.e., he might have wanted to make vowel contrast in such variants as great as possible.

10. Nasaling. Nasaling, different from nasalization — a process by which an oral stretch of utterance is nasalized - is a change from a non-nasal, usually liquids $[\lambda]$ and $[\rho]$ in final position, to the velar nasal $[\mathrm{N}]$. This process was found in 40 (8.29\%) of Mara's, 52 (9.90\%) of Mogi's, and $140(7.39 \%)$ of Mika's variants. Examples are [v $\delta \alpha \mathrm{N}]$ for sendal

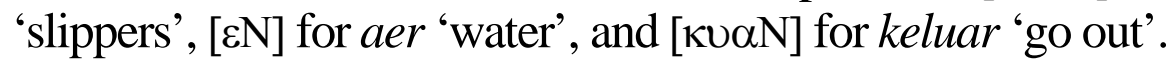

11. Raising. A relatively low vowel is changed to a relatively high one. This process was not used by Mara or Mogi, and was found in 69 (3.64\%) of Mika's variants. Examples are [ $1 v \delta \alpha \mathrm{N}]$ for sendal 'slippers'

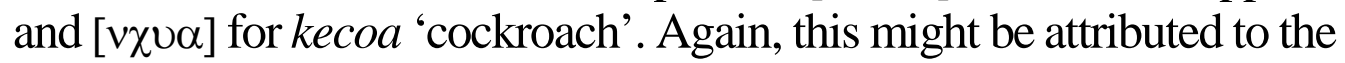
child's attempt to maximize contrast between the two vowels in each words.

12. Stopping. A fricative or affricate is changed to a stop. This process was found in 9 (1.86\%) of Mara's, 28 (5.33\%) of Mogi's, and 30 (1.58\%)

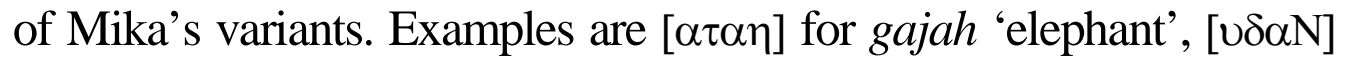

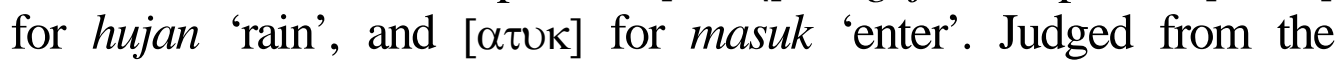
difference in the percentage, it seems that Mogi had a clear preference for this particular process. However, judged from age difference between Mogi and Mika at the time of their separate observation and given the fact that Mara might be showing an advanced phonological development, it might also be the case that this process, like Process 1 Affricating, is preferred by younger children.

13. Vocalization. Claimed to be particularly unique to English (Ingram, 1986), this process turned out to be utilized by none of the three Indonesian children.

14. Voicing. A voiceless consonant is changed to the homorganic voiced one, without any apparent influence from the surrounding speech sounds. This process was not used by Mara or Mogi, and was found in $14(.74 \%)$ of Mika's variants. Examples are $[\alpha \beta \alpha]$ for Bapak 'Father' and [u甲v] for susu 'milk'. 
15. Vowel Neutralization. A relatively front or back vowel is changed to a central one. This process was found in 9 (1.86\%) of Mara's, 7 (1.33\%) of Mogi's, and none of Mika's variants. Examples are [ $\left.v_{\varepsilon} \mathrm{N}\right]$ for minggir 'get out of the way' and $[\beta \alpha \mathrm{N}]$ for belum 'not yet'. This process was not found in Mika's corpus, perhaps since in the analysis of his variants more attention was paid to the change in the height of tongue position-high, mid, and low, thus Processes 9 Lowering and 11 Raising.

16. Zeroing. Liquids $[\lambda]$ and $[\rho]$ are deleted especially in medial positions. Sometimes a diacritic lengthening [\rceil$]$ is utilized. This process was found in 19 (3.94\%) of Mara's, 12 (2.28\%) of Mogi's, and 129 (6.81\%) of Mika's variants. Examples are $[\leftrightarrow 1]$ for geli 'itchy', $[\beta \leftrightarrow 1$ ] for beli 'buy', and $[\mu \alpha\rceil \alpha]$ for Mara 'Elder Brother Mara'. Judged from the percentage difference, it seems that when dealing with liquids Mika had a slightly greater preference for this process compared to the other two.

\section{Assimilation}

Assimilation is context-motivated, i.e., it is a sound change which is held to occur because of the influence of the neighboring sounds. As many as eight processes fall within this sub-class: Process 17 through Process 24. 17.Alveolar Assimilation. A non-alveolar consonant is changed to an alveolar because of a neighboring alveolar. This process was found in 13 (2.69\%) of Mara's, 4 (.76\%) of Mogi's, and 15 (.79\%) of Mika's

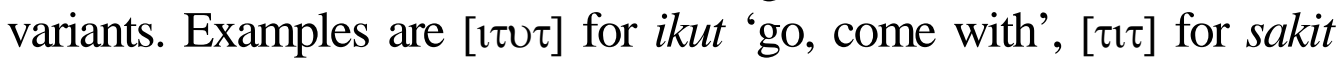
'painful, sick', and [v $\delta \alpha \delta \alpha]$ for $n g g a d a$ 'non-existent'.

18.Denasalization. This process, in which a nasalized stretch of sounds is made denasalized, was not utilized by the three Indonesian children. From the examples provided by Ingram (1986), it may be inferred that this process is characteristic to French.

19. Glottal Assimilation. A non-glottal consonant is changed to a glottal because of the existence of a glottal consonant. This process was found in $6(1.24 \%)$ of Mara's variants and not found in Mogi's and Mika's

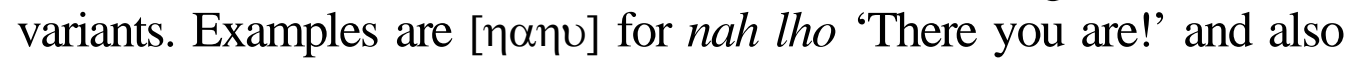

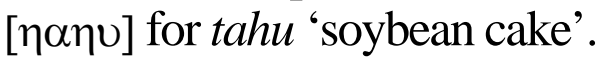

20.Labial Assimilation. A non-labial consonant is changed to a labial consonant because of a neighboring labial. This process was found in 3 (.62\%) of Mara's, none of Mogi's, and 7 (.37\%) of Mika’s variants. 
Examples are $[\alpha \pi \leftrightarrow \pi]$ for asep 'smoke' and $[\alpha \mu \mu]$ for salim 'handkiss'.

21. Stop Deletion. A stop consonant is deleted because of a neighboring nasal. This process was found in 20 (4.14\%) of Mara's, 1 (.19\%) of Mogi's, and 14 (.74\%) of Mika's variants. Examples are [ $\alpha \mu \alpha \eta]$ for

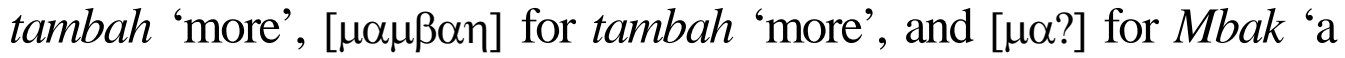
term of address'.

22. Velar Assimilation. A non-velar consonant is changed to a velar one because of a neighboring velar consonant. This process was found in 2 (.41\%) of Mara's, 3 (.57\%) of Mogi's, and 53 (2.80\%) of Mika's

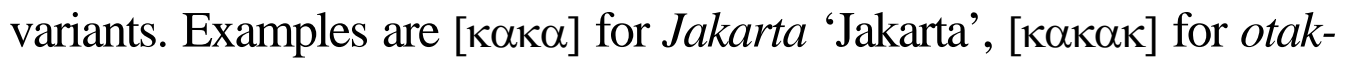
otak 'fish cake', and [Nкטк] for ikut 'go, come with'.

23. Voicing. A voiceless consonant is changed to a voiced one because of a preceding nasal or the surrounding back vowels. This process was found in 1 (.20\%) of Mara's, 1 (.19\%) of Mogi's, and none of Mika's

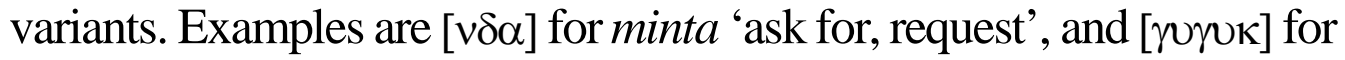
ketok 'hit, knock'.

24. Vowel Assimilation. In Ingram's outline, this change happens to a certain vowel because of the existence of another vowel or a consonant. This process was found in 9 (1.86\%) of Mara's, 12 (2.28\%) of Mogi's, and 68 (3.59\%) of Mika's variants. Examples are [ $\pi \leftrightarrow \pi \leftrightarrow \tau]$ for copot

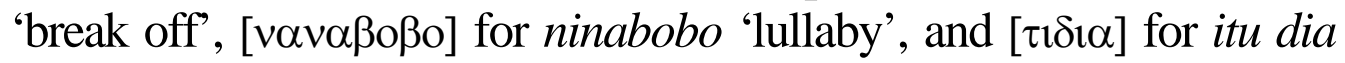
'there it is'.

\section{Syllable Structure Process}

This is a sound change which is thought to be brought about by changes children make in syllable structures. Under this sub-class, there are nine processes: Process 25 to Process 33.

25. Addition. A consonant is added at the beginning of a word or a syllable resulted from other syllable structure processes, notably Processes 32 Unstressed Syllable Deletion and 33 Unstressed Syllable Substitution. This process was found in none of Mara's, 20 (3.81\%) of Mogi's, and $29(1.53 \%)$ of Mika's variants. Examples are $[\mu \beta \mathrm{l}]$ for beli 'buy' and $[\mu \beta o ß o]$ for bobo 'sleep'. Judged from the difference in the percentage, it seems that Mogi had a preference for this particular process.

26. Cluster Reduction. A consonant cluster is reduced by deleting one consonant. This process was found in $5(1.03 \%)$ of Mara's, 1 (.19\%) of 
Mogi's, and 17 (.90\%) of Mika's variants. Examples are [ $\tau \leftrightarrow \kappa]$ for truk 'truck', [ $\tau \mathrm{vN}]$ for setrum 'electricized', and $[\alpha \beta \alpha \kappa]$ for tabrak 'bump, collide'. Judged from the difference in the percentage, it seems that Mogi might have avoided producing adult words constructed with a consonant cluster.

27. Deletion With Retention. An unstressed syllable is deleted, but the first consonant of the deleted syllable is retained and replaces the first consonant of the remaining syllable. This process was found in 1 (.20\%) of Mara's, 59 (11.24\%) of Mogi's, and 34 (1.79\%) of Mika's

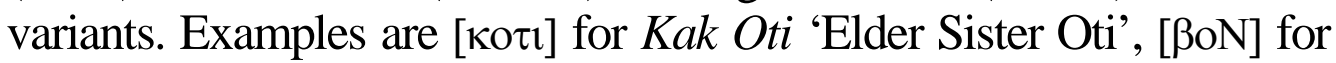
balon 'balloon', and [ $\tau \leftrightarrow \pi \mathrm{oN}]$ for telepon 'telephone'. Judged from the difference in the percentage, it seems that Mogi had a preference for this particular process.

28. Final Consonant Deletion. A final consonant is deleted from a word or a syllable. This process was found in 5 (1.03\%) of Mara's, 17 (3.24\%) of Mogi's, and 66 (3.48\%) of Mika's variants. Examples are [o $\lambda \mathrm{o}$ ] for bolong 'holed, hollow', $[\beta \alpha \beta \alpha]$ for Allahuakbar 'Allah the Greatest',

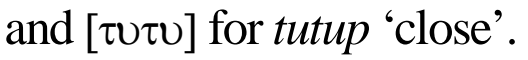

29. Final Vowel Deletion. A final vowel is deleted from a word or a syllable. This process was found in none of Mara's, none of Mogi's, and $2(.11 \%)$ of Mika's variants. They are $[\tau \iota v]$ and $[\tau \imath \mathrm{N}]$ for Tini 'Tini, a house maid'.

30. Initial Consonant Deletion. An initial consonant is deleted from a word or a syllable. This process was found in 189 (39.21\%) of Mara's, 62 (11.81\%) of Mogi's, and 665 (35.09\%) of Mika's variants. Examples are $[\alpha v \alpha]$ for mana 'where', [i $i \propto \alpha]$ for Aa Mirza 'Elder Brother Mirza', and $[1 v \cup \mu]$ for minum 'drink'. Judged from the great difference in the percentages, it seems that Mogi decidedly had an idiosyncratic preference against this process. As it turned out, he was more inclined to delete whole unstressed syllables rather than the initial consonants of unstressed syllables (see Process 32 Unstressed Syllable Deletion). On the other hand, taken into account the age differences between Mogi and Mika at the time of their separate observation and the observation that Mara might have been displaying an advanced phonological development, it might be the case that Process 30 Initial Consonant Deletion is characteristically preferred by older children.

31. Reduplication. A syllable, usually resulting from Process 32 Unstressed Syllable Deletion, is repeated. This process was found in 52 (10.78\%) of Mara's, 73 (13.90\%) of Mogi's, and 88 (4.64\%) of Mika’s variants. 


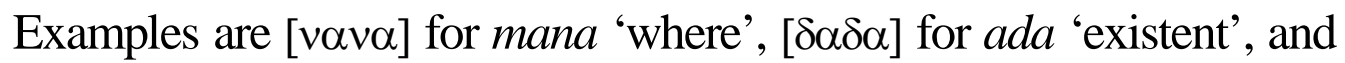
[v $\alpha v \alpha \mu]$ for minum 'drink'. Judged from the difference in the percentage, it seems that Mika had a preference against this particular process.

32. Unstressed Syllable Deletion. A syllable, usually the first of bi- and multi-syllabic words, is deleted. This process was found in 159 (32.98\%) of Mara's, 338 (64.38\%) of Mogi's, and 490 (25.86\%) of Mika's variants. Examples are [Nov] for jangan 'don't', [8v] for baju 'shirt, clothe', and $[\delta \leftrightarrow \Sigma]$ for pedes 'chilly hot'. Judged from the difference in the percentage, it seems that undeniably Mogi had a great preference for this particular process. As observed previously, Mogi had a relative preference against Process 30 Initial Consonant Deletion. If these are put together, it might seem that when facing adult multisyllabic words he idiosyncratically chose to delete unstressed syllables altogether. On the other hand, taken into account the age differences between Mogi and Mika at the time of observation and the estimation that Mara might have been displaying an advanced phonological development, it might be the case that Process 32 Initial Consonant Deletion is characteristically preferred by younger children. 33. Unstressed Syllable Substitution. An unstressed syllable is deleted and in its place a vowel or a homorganic nasal is uttered. This process was found in 72 (14.93\%) of Mara's, 71 (13.52\%) of Mogi's, and 288 (15.20\%) of Mika's variants. Examples are $[\mu \beta v]$ for Ibu 'Mother',

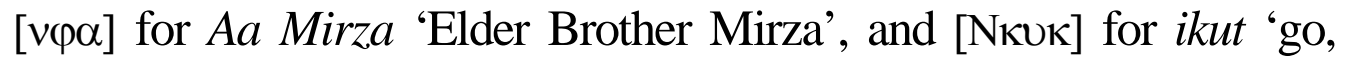
come with'. Judged from the percentages, it seems that all three had a preference for this process.

\section{Aged-Related Phonological Processes}

It might be possible that phonological process utilization varies in accordance with age not only in quantity but also in quality. Stampe, quoted in Ingram (1986), regards children's phonological development as a gradual loss of these simplifying processes. In other words, the quantity of phonological processes that children apply to simplify adult language words decreases as they become phonologically more mature, and when they have completed their phonological acquisition there will be practically none of these processes in their language. This quantitative development could reasonably be appreciated. However, as long as phonological process is concerned, the changes children go through as they grow up might also be qualitative. That is, there might be certain phonological processes that 
children tend to use at a very early stage of acquisition, and there might as well be certain different phonological processes that children are inclined to use at later stages.

By first looking at age difference between Mogi and Mika, by secondly considering the observation that Mara might have been showing a little more advanced phonological development, and by thirdly inspecting phonological process utilization percentage differences, it could be forwarded that Affricating, Stopping, and Unstressed Syllable Deletion might likely be processes which younger children acquiring Indonesian tend to utilize, while Initial Consonant Deletion might likely be one which older Indonesian children are inclined to use. Needless to say, further studies are required to shed more light on this matter.

\section{Universal Phonological Processes}

By comparing, on the one hand, the original fourteen processes outlined by Ingram (1986) and, on the other hand, the phonological processes utilized by the three Indonesian children, a number of things could be inferred. First of all, there is one process utilized with high frequency by the three Indonesian children and also reported to be commonly used among children acquiring Indo-European languages. This process - Unstressed Syllable Deletion - might very likely be universal, i.e., species-specific, meaning that any child acquiring any human language might be found to use this particular process in phonologically simplifying adult language words.

Second, there are two processes reported to be commonly used among children acquiring Indo-European languages (Ingram 1986) which are not found in the three Indonesian children's corpus. These processesVocalization and Denasalization-might very likely be language-specific to Indo-European languages, particularly English and French.

On the other hand, there are at least three processes utilized with high productivity by the three Indonesian children but not reported to be commonly used among children acquiring Indo-European languages. These processes-Nasaling, Initial Consonant Deletion, and Unstressed Syllable Substitution-might very likely be language-specific to Indonesian, perhaps even to Western-Austronesian languages.

Third, based on further examination on the three Indonesian children's phonological processes, it could be forwarded that each of them was 
observed to demonstrate a definite preference for as well as against certain processes. For example, Mogi seems to show a relative preference for Deletion with Retention and Unstressed Syllable Deletion and a relative preference against Initial Consonant Deletion, while Mara and Mika both seem to show the opposite: a relative preference against Deletion with Retention and Unstressed Syllable Deletion and a relative preference for Initial Consonant Deletion. This suggests that these processes might very likely be individual-specific, or idiosyncratic.

\section{CONCLUSION}

The present paper has presented and discussed the processes used by three Indonesian children in phonologically simplifying the target language words. In conclusion, it could be restated that phonological process utilization might be related with age not only in quantity but also in quality. Secondly, it could also be reasserted that, although Stampe (quoted in Ingram, 1986) might be right in postulating that the phonological processes are universal, it seems that the universality should at best be accepted as a continuum, meaning that some processes are universal or species-specific, some others are local or language-specific, and still some others are idiosyncratic or individual-specific.

\section{REFERENCES}

Carroll, D. W. (1986). Psychology of language. Pacific Grove, California: Brooks/Cole Publishing Company.

Cruttenden, A. (1979). Language in infancy and childhood. New York: Holt, Rinehart and Winston.

Crystal, D. (1987). The Cambridge encyclopedia of language. Cambridge: Cambridge University Press.

Dale, P. S. (1976). Language development: Structure and function. New York: Holt, Rinehart and Winston.

Faingold, E. D. (1990). The acquisition of syllabic and word structure: Individual differences and universal constraints. Language Sciences, 12(1), 101-113. 
Ferguson, C. A., \& Garnica, O. K. (1975). Theories of phonological development. In E. H. Lenneberg, \& E. Lenneberg (Eds.), Foundations of language development: A multidisciplinary approach (vol. 1) (pp. 153-180). New York: Academic Press.

Ingram, D. (1986). Phonological development: Production. In P. Fletcher, \& M. Garman, (Eds.), Language acquisition: Studies in first language development (pp. 223-239). Cambridge: Cambridge University Press.

Ingram, D. (1989). First language acquisition: Method, description, and explanation. Cambridge: Cambridge University Press.

Menyuk, P., Menn, L., \& Silber, R. (1986). Early strategies for the perception and production of words and sounds. In P. Fletcher, \& M. Garman (Eds.), Language acquisition: Studies in first language development (pp. 198-222). Cambridge: Cambridge University Press.

Raja, P. (1998). The phonological processes of a twenty-month-old child, Jurnal Pendidikan Humaniora dan Sains Tahun 4 No 1\&2 April-September 1998, 24-49.

Raja, P. (2000). Word simplification processes in the telegraphic stage. Paper presented at The Fourth International Symposium on Malay/Indonesian Linguistics (ISMIL 4), Jakarta, Indonesia.

Raja, P. (2003). The language of an Indonesian child named Mika in the telegraphic and simple sentence stages. Unpublished doctoral dissertation, Malang State University, Malang. 